\title{
НИЗКОТЕМПЕРАТУРНЫЕ СПЕКТРЫ ИЗЛУЧЕНИЯ КИСЛОРОДА В ЩЕЛОЧНОГАЛОИДНЫХ КРИСТАЛЛАХ
}

Спектры люминесценции активированных кислородом щелочногалондных кристаллов привлекают внимание своей четкой колебательной структурой, которая ярко выражена даже при комнатной температуре [1-4]. При гелиевых температурах обнаружено, что каждая из колебательных полос электронно-колебательного спіектра обладает «тонкой структурой» $[5,6]$. С целью дальнейшего изучения этой структуры и выяснения ее природы нами проведено более детальное измерение спектров люминесценции при температуре $4,2^{\circ} \mathrm{K}$.

Обнаружен ряд новых деталей спектров (от трех до десятка четких максимумов). Эту структуру следует, на наш взгляд, считать обусловленной в основном взаимодействием электронного перехода в примесной молекуле $\mathrm{O}_{2}^{-}$с искаженными ею кристаллическими колебаниями.

Фосфоры были получены быстрым охлаждением расплавленной смеси щелочногалоидной соли основания и навески кислородсодержащей соли и имели поликристаллическое строение. Исходные соли $\mathrm{KCl}$ и $\mathrm{KBr}$ брались марки «особо чистый»; соль $\mathrm{NaBr}$ и соли активатора $\mathrm{NaHCO}_{3}$ и $\mathrm{KHCO}_{3}$ - марки ЧДА. Концентрации соли активатора варьировались от 0,5 до 2 мол.\%.

Спектры люминесценции фотографировались на спектрографе ИСП-67 с камерой $F=500$ м.. Относительное отверстие объектива было $1: 5,2$. Линейная дисперсия для $\lambda=4861 \AA$ была $21,8 \AA / \mu м ;$ в области $6000 \AA$ она составляла $\sim 40 \AA /$ м. С. Спктр фотографировался на пленку РФ-3; спектральная чувствительность пленки была такова. что участок с $\lambda>6500 \AA$ не регистрировался. Образцы помещались в стеклянный крностат, в нижний оттянутый конец которого был впаян поясок из увиолевого стекла. Оня находились непосредственно в жидком гелии и люминесценция снималась через слой жидкого гелия и азота. Свечение возбуждалось ртутно-ксеноновой лампой типа ГСВД-120 через стеклянный фильтр УФС-2. Спектром сравнения служил спектр железной искры, по линиям которой на компараторе определялось положение максимумов в спектре люминесценции. Приводимые записи почернения, снятые на микрофотометре МФ-4, дальнейшим исправлениям не подвергались.

На рис. 1 приведена микрофотограмма участка спектра излучения $\mathrm{NaBr}-\mathrm{O}_{2}$ с дву мя колебательными группами (главные максимумы с $\lambda=5231$ и $5522 \AA ̊$ ). Структура в спектрах $\mathrm{KCl}-\mathrm{O}_{2}$ и $\mathrm{KBr}-\mathrm{O}_{2}$ демонстрируется на рис. 2 и 3. Для лучшего выявления деталей спектры снимались с экспозициями, при которых наиболее интенсивные (главные) максимумы были переэкспонированы. Видно, что структура в обеих группах во всех деталях (за исключением одной линии в $\mathrm{KBr}-\mathrm{O}_{2}$, см. ниже) одинакова. Хорошая повторяемость структуры в различных группах является характерной чертой всех изученных нами групп.

Положения всех зарегистрированных максимумов сведены в таблице. Там же даны выраженные в волновых числах расстоянкя максимумов от наиболее коротковолнового максимума своей группы. Эти расстояния в различных группах одного фосфора следует считать совпадающими: хотя у некоторых из них можно усмотреть тенденцию к убыванию по мере перехода к длинноволновым группам, эффект не превышаеі ошибку опыта. Исключением является узкая линия в конце колебательной группы $\mathrm{KBr}-\mathrm{O}_{2}$, которая смещается приблизительно по линейному закону, сдвигаясь на 20-30 см-1 при переходе к соседней группе. 

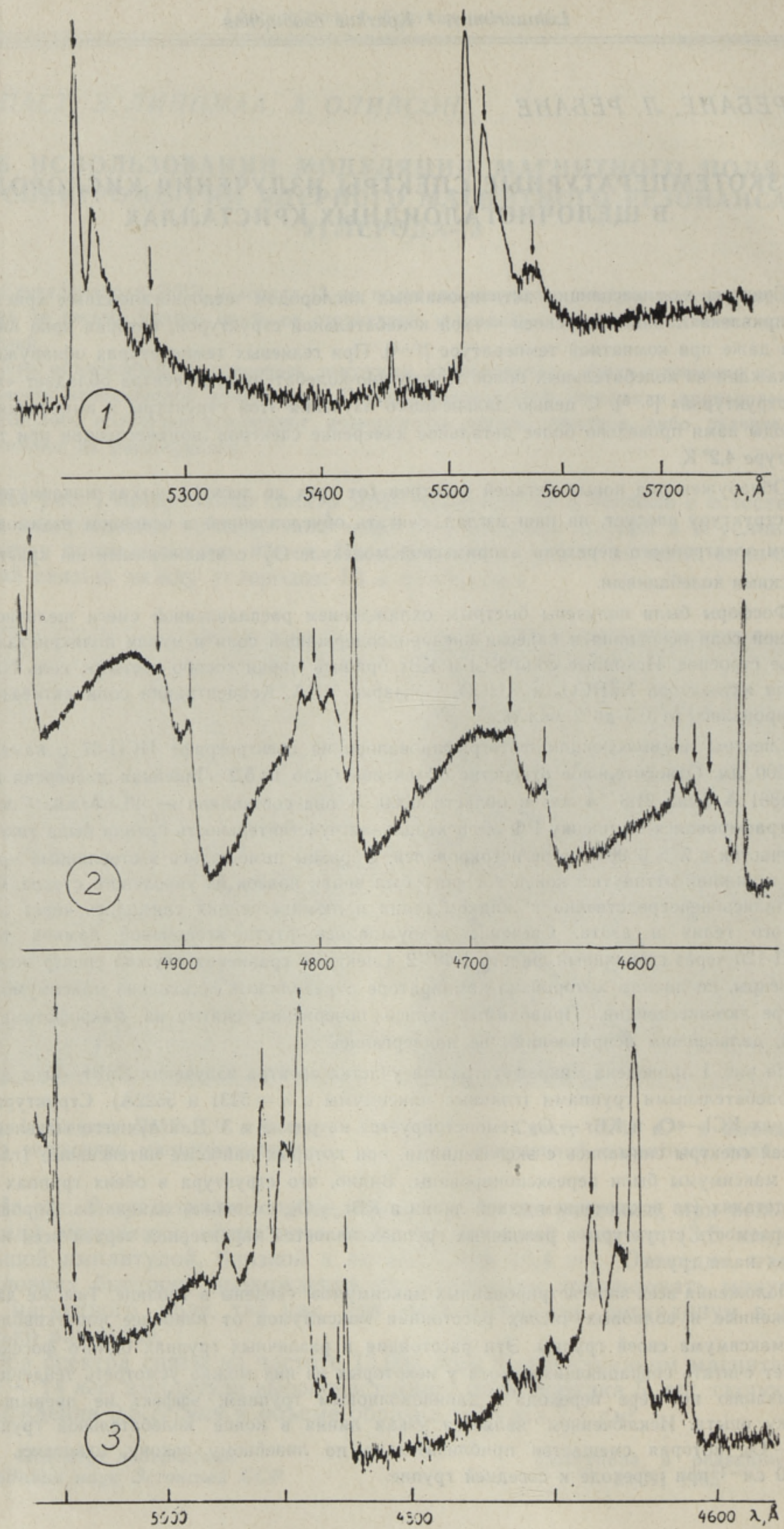
$\mathrm{KBr}-\mathrm{O}_{2}$

$\Delta \omega_{c p}$

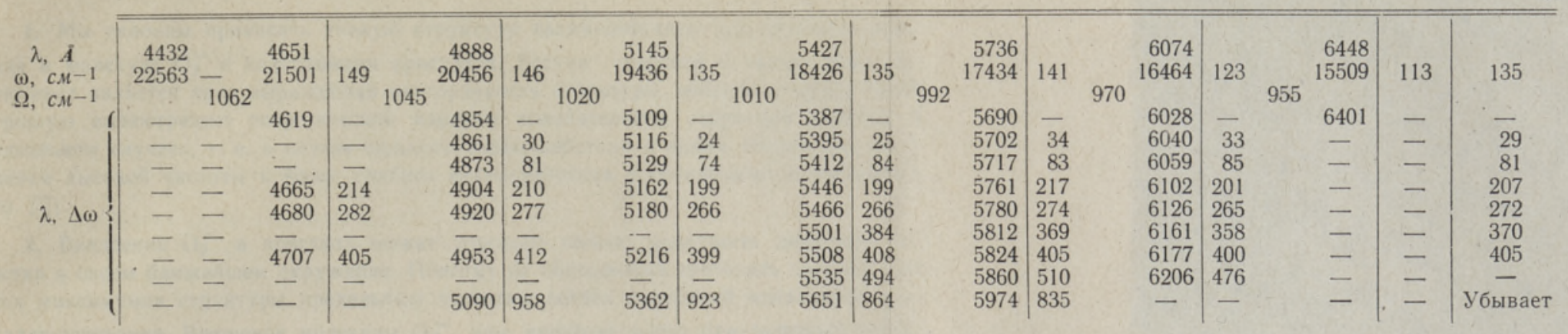

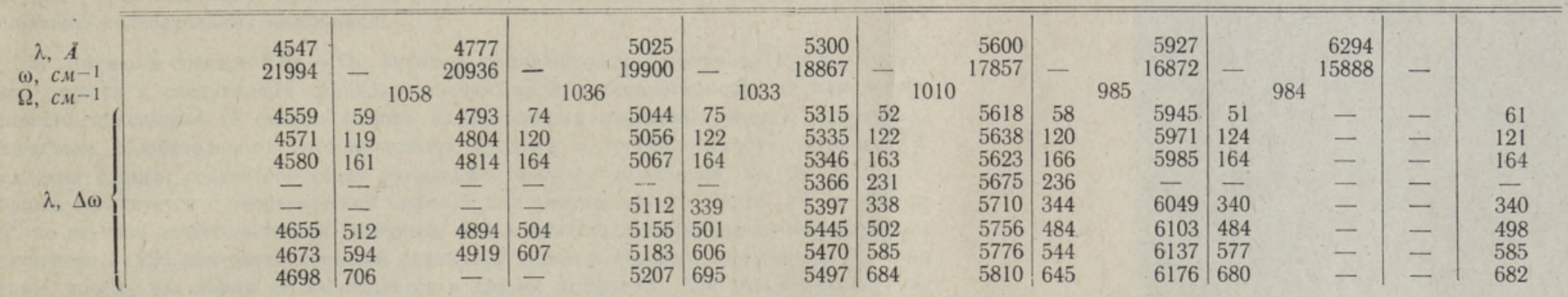

$\mathrm{NaBr}-\mathrm{O}_{2}$

\begin{tabular}{|c|c|c|c|c|c|c|c|c|c|c|c|c|c|c|c|c|c|c|}
\hline $\begin{array}{c}\lambda, \vec{A} \\
\omega, c M^{-1} \\
\Omega, c M^{-1}\end{array}$ & $\begin{array}{r}4721 \\
21182\end{array}$ & & $1045^{2}$ & $\begin{array}{r}4966 \\
20137\end{array}$ & & 1020 & $\begin{array}{r}5231 \\
19117\end{array}$ & - & 1008 & $\begin{array}{r}5522 \\
18109\end{array}$ & & $989^{1}$ & $\begin{array}{r}5841 \\
17120\end{array}$ & & 968 & $\begin{array}{r}6191 \\
16152\end{array}$ & & \\
\hline$\lambda, \Delta \omega$ & 二 & E & 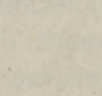 & $\bar{z}$ & - & & $\begin{array}{l}5243 \\
\frac{-}{5280}\end{array}$ & $\frac{44}{188}$ & 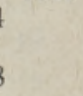 & $\begin{array}{l}5535 \\
5552 \\
5578\end{array}$ & $\begin{array}{r}42 \\
97 \\
181\end{array}$ & & $\begin{array}{l}5855 \\
5872 \\
5905\end{array}$ & $\begin{array}{r}41 \\
90 \\
185\end{array}$ & & $\frac{6208}{-}$ & $\begin{array}{l}44 \\
-\end{array}$ & $\frac{43}{185}$ \\
\hline
\end{tabular}

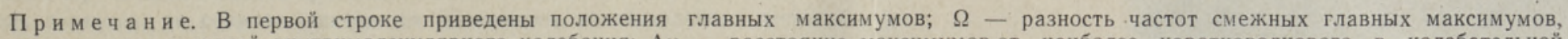

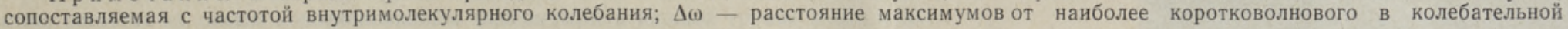
группе.

Рис. 1. Микрофотограмма участка спектра излучения $\mathrm{NaBr}-\mathrm{O}_{2}$ при $4,2^{\circ} \mathrm{K}$, содержащего две колебательные группы $(\lambda=5231$ и $5522 \AA \AA)$. Максимумы, отмеченные стрелками, приведены в таблице.

Рис. 2. Микрофотограмма участка спектра излучения $\mathrm{KCl}-\mathrm{O}_{2}$ при $4,2^{\circ} \mathrm{K}$, содержащего две колебательные группы $(\lambda=4547$ и 4777 A $)$. Максимумы, отмеченные стрелками, приведены в таблице.

Рис. 3. Микрофотограмма участка спектра излучения $\mathrm{KBr}-\mathrm{O}_{2}$ при $4,2^{\circ} \mathrm{K}$, содержащего две колебательные группы $(\lambda=4651$ и $4888 \boldsymbol{A})$. Максимумы, отмеченные стрелками, приведены в таблице. 


\section{Предварительная интерпретация и выводы}

1. Мы склонны приписать тонкую структуру взаимодействию электронного пере хода в молекуле $\mathrm{O}_{2}^{-}$с колебаниями кристалла. Веским доводом в пользу этого заключения является ярко выраженная повторяемость структуры, представляющая собой хорошую иллюстрацию теоретической картины колебательной структуры спектра в «идеальном случае», т. е. в случае сильного взаимодействия с одним локальным колебанием высокой частоты и более слабого взаимодействия с остальными колебаниями (сp. [7]).

2. Внедрение $\mathrm{O}_{2}^{-}$в кристалл может довольно сильно возмущать динамику решетки в своем ближайшем окружении. Поэтому не обязательно требовать соответствия всех максимумов структуры предельным частотам ветвей колебаний идеального кристалла-основания. Вращение молекулы $\mathrm{O}_{2}^{-}$, еще имеюшее место при гелиевых температурах [ $\left.{ }^{8}\right]$, по-видимому, приводит в рассматриваемых спектрах к дополнительному уширению колебательных квазилиннй.

3. Линию в спектре $\mathrm{KBr}-\mathrm{O}_{2}$, линейно смещающуюся с номером группы, заманчиво отнести к следующему главному максимуму и интерпретировать ее как копию главного максимума (в смысле набора колебательных квантовых чисел), сдвинутого вследствие колебательного изотопического эффекта в коротковолновую сторону [ $\left.{ }^{9}\right]$. Величина сдвига, соответствующая изменению частоты колебания на $20-30 \mathrm{~cm}^{-1}$, хорошо согласуется с теоретической оценкой для замены одного атома О ${ }^{16}$ на изотоп $\mathrm{O}^{18}$, но не ясно, соблюдается ли требуемое для естественной смеси нзотопов кислорода отношение $1: 250$ для интенсивностей сдвинутой линии и главного максимума. Не ясно также, почему эта линия не наблюдается в других фосфорах. Для закономерного линейного сдвига «копин» главного максимума нужно, в конечном счете, изменение частоты внутримолекулярного колебания $\mathrm{O}_{2}^{-}$, которое может быть вызвано и другими при. чинами.

4. Возможно, что некоторую роль в образовании структуры играет расщепление электронных термов, но пока нет необходимости привлекать это явление к интерпретации спектров. Действительно, если считать, что главные максимумы в спектре $\mathrm{KBr}-\mathrm{O}_{2}$ возникают в результате комбинации с электронным переходом $n$ квантоз колебания $\mathrm{O}_{2}^{-}$и одного кванта кристаллического колебания с частотой около $140 \mathrm{~cm}^{-1}$. то роль перехода, не сопровождающегося изменением колебательного состояния решетки, остается за самым коротковолновым максимумом в каждой группе и отпадает необходимость в интерпретации антистоксового крыла. Вполне допустимо считать, что в $\mathrm{KBr}-\mathrm{O}_{2}$ безразмерные стоксовы потери больше единицы. Это допущение также объясняет большую протяженность колебательного спектра, заметно превышающую максимальную предельную частоту колебания кристалла основания. Однако пока не ясно, удовлетворяют ли интегральные интенсивности следующих членов в серии линий по колебанию $140 \mathrm{~cm}^{-1}$ соотношениям для факторов Франка-Кондона. Если не удовлетворяют, то приходится, по-видимому, привлечь для интерпретации расщепление электронного терма.

5. Из сравнения структуры спектров $\mathrm{KBr}-\mathrm{O}_{2}, \mathrm{KCl}-\mathrm{O}_{2}$ и $\mathrm{NaBr}-\mathrm{O}_{2}, \mathrm{NaCl}-\mathrm{O}_{2}$ [5, 6] хорошо видно, что проявляющаяся в спектре локальная динамика решетки определяется катионом основания, как это и должно быть при размещении $\mathrm{O}_{2}^{-}$в анионном узле решетки $\left.{ }^{8}\right]$. Взаимодействие с кристаллическими колебаниями сильнее в случае калия, чем натрия.

Авторы благодарны Е. Ф. Гроссу и сотрудникам его лаборатории за предоставленную возможность выполнить измерение спектров.

Авторы особенно признательны Б. П. Захарчене за ценные советы и И. И. Тахистовой за участие в измерениях. 


\section{ЛИТЕРАТУРА}

1. Honrath W., Ann. Phys., 29, 421 (1937).

2. Ak p in a r S., Ann. Phys., 37, 429 (1940).

3. E w les J., B a r m b y D., Proc. Phys. Soc. (London), B 69, 670 (1956).

4. Ш м и т с О., 3 а к и с Ю., Изв. АН СССР, Сер. физ., 25, 385 (1961).

5. Rolf e J., Li psett F., King W., Phys. Rev., 123, 447 (1961).

6. R o 1 f e J., J. Chem. Phys., 40, 1664 (1964).

7. Ребане К. К., Теория оптических электронно-колебательных переходов в примесном центре кристалла, Тартуский гос. ун-т, ротапринт. 1963.

8. Kä n z i g W., J. Phys. Chem. Solids, 23, 479 (1962).

9. Р еб н н К. К., Тр. XVI Совещания по спектроскопии, т. III (в печати).

Low-temperature emission spectra of oxygen in alkali halide crystals.

Институт физики и астрономии Академии наук Эстонской ССР

\section{Поступила в редакцию $8 /$ VI 1965}

\section{ÜLEVAATEID * ОБЗОРЫ}

\section{OLELIIDULINE POOLJUHTIDE TEOORIA ALANE NOUPIDAMINE}

Käesolev nõupidamine toimus Kišinjovis oktoobris 1964. Sellest vōttis osa üle 200 teadlase, nende hulgas ka eksperimentaatoreid. Perekamad delegatsioonid olid saabunud Moskvast, Leningradist, Kiievist, Sverdlovskist, Tbilisist ja Harkovist. Eesti NSV teadlastest avanes võimalus konverentsist osa vôtta Teaduste Akadeemia korrespondentliikmel K. Rebasel ning V. Hižnjakovil, I. Tehveril ja allakirjutanul akadeemia Füüsika ja Astronoomia Instituudist. Viimaseil aastail on pooljuhtide teooria alal aktiivselt töötanud Kišinjovi noored teadlased, kes esitasid ka arvukalt ettekandeid. Konverentsi korraldamine nende kodulinnas oli selle töö tunnustuseks.

Organiseeriv komitee oli konverentsile esitatud originaaluurimused klassifitseerinud temaatika järgi ning andnud ettekandjate, nn. reporterite käsutusse. Viimased esinesid plenaaristungitel ulatuslikumate ettekannetega, milles andsid ülevaate neist töödest vastava probleemi uurimisolukorra taustal. Piiratud arv autoreid said sōna tähtsamate uurimistulemuste esitamiseks ōhtustel sektsioonide istungeil.

Tänu ka nõupidamise sellisele organiseerimisele kristalliseerusid suhteliselt selgesti välja pooljuhtide teooria aktuaalsed uurimissuunad. 1962. aastal Bakuus toimunud konverentsiga võrreldes vōib konstateerida käsitletava küsimusteringi ahenemist tõe- poolest aktuaalsete ja praktikale vajalike suundade kasuks ning samal ajal märkida uurimistööde olulist süvenemist. Pooljuhtseadmed jäävad endiselt tehnika eeslinile, nagu märkis sissejuhatavas sōnavōtus Ukraina NSV Teaduste Akadeemia akadeemik S. P e k a r. Seda eelkōige peamiselt seetōttu, et nad on väliste mōjutuste suhtes vôrratult tundlikumad kui näiteks metallid. Piisab, kui öelda, et pooljuhtidel töötavate termoelementide kasutegur on viidud 8 protsendini. Kui seda kasutegurit ōnnestub kolmekordistada, mis peaks olema reaalne, hakkavad looduslikel temperatuuride vahel töötavad pooljuhtseadmed välja tōrjuma söeelektrijaamu.

Konverentsil käsitletud aktuaalsetest probleemidest tuleb eelkõige märkida plasmaefektide uurimist pooljuhtides. Reporteriettekande selle kohta esitas L. Gureviťs (Leningrad). Kui pooljuhis on tekitatud küllaldasel hulgal laengukandjaid, võivad neis levida nn. plasmavõnkumised. Viimased omakorda mõjutavad mitmesuguseid teisi pooljuhis levivaid laineid, näit. elektromagnetilisi, tehes seda sobivatel tingimustel selliselt, et neid laineid on vôimalik võimendada. Analoogiline olukord esineb ka ultrahelilainete puhul (V. Gurevitš, Leningrad). Seda laadi uurimistööd on tihedalt seotud ülekandenähtuste kvantteooriaga (reporter A. Efros, Leningrad). 